\title{
XXX. Notes on photographs of rapidly moving objects, and on the oscillating electric spark
}

\author{
C. V. Boys A.R.S.M. F.R.S.
}

To cite this article: C. V. Boys A.R.S.M. F.R.S. (1890) XXX. Notes on photographs of rapidly moving objects, and on the oscillating electric spark , Philosophical Magazine Series 5, 30:184, 248-260, DOI: $10.1080 / 14786449008620020$

To link to this article: http://dx.doi.org/10.1080/14786449008620020

册 Published online: 08 May 2009.

Submit your article to this journal ¿

Цll Article views: 6

Q View related articles $\square$

Citing articles: 1 View citing articles 5 


\section{Prof. C. V. Boys on Photographs of Rapidly Moving}

and upwards, the $b$ and $c$ curves for the same linear current of 2 amperes tend to terminal coincidence, but diverge at the intermediate stages. It is proposed to study more fully these relations, and to extend the investigations to nickel and cobalt.

In the course of these experiments an effect was noticed which demonstrates the extraordinary complexity of magnetic distribution in a magnetized wire. If, before the wire has been magnetized at all, a current is passed along it no appreciable longitudinal polarity is produced, as measured by a magnetometer-needle placed as in the above experiments. Suppose, however, that the wire has been pretty strongly magnetized; and that, in the manner discovered by Auerbach, and used almost universally now, the wire is demagnetized by reversals of gradually diminishing magnetizing currents until the magnetometer-needle stands almost exactly at zero. It is of course generally recognized that the wire so demagnetized cannot be regarded as being in anything like the same condition as it was in its originally unmagnetized state, although it appears to have lost polarity. That this view is correct may be at once demonstrated by simply passing a pretty strong current along the wire, when a very pronounced polarity will be evidenced by a comparatively large deflexion of the magnetometer-needle. Reversing the current will reverse this polarity. Heating to a red heat can alone truly demagnetize an iron wire.

Imperial University, Tokyo, May 30, 1890 .

XXX. Notes on Photographs of Rapidly Moving Objects, and on the Oscillating Electric Spark. By C. V. Boys, A.R.S.M., F.R.S., Assistant Professor of Physics at the Normal School of Science and the Royal School of Mines, South Kensington*.

[Plate VI.]

1. T HAD occasion last Christmas to show to a juvenile audience a modification by the late Dr. Guthrie of one of Plateau's experiments, which beautifully illustrates the effect of the surface-tension of a liquid during the growth and formation of a drop. Under ordinary circumstances a drop of water is so small that the formation of the neck and separation of the drop are too rapid for it to be possible to follow the process by the eye. If the drops were larger the process would be slower, but a larger drop, owing to the weight of water, cannot be formed in air. Dr. Guthrie caused the drop

- Communicated by the Physical Society : reed May 2, 1890. 
to grow at the end of a pipe half an inch or so in diameter dipped below the surface of paraffin. By this means the effective weight of the drop is very much reduced, and the surface tension is reduced, so that a large drop can be formed, and the process is made comparatively slow. I have found that the development of the drop can be made still more gradual, and that still larger drops may be formed by adding bisulphide of carbon to the paraffin so as further to reduce the effective weight of the drop.

While trying to devise some way of representing this experiment on paper, I saw at the Royal Institution an apparatus exhibited by Mr. Friese Greene, with which photographs at the rate of ten a second could be taken upon a travelling film moved on between and stopped during each exposure.

Examination of the growing drop through a small window in a card disk made to rotate ten times a second, showed that even this rate applied to large and slowly forming drops was not sufficient to give anything like a continuous representation of the forms assumed. However, I found no difficulty in obtaining twenty photographs a second; and, had I required them, I could certainly have obtained fifty sharp and fully exposed photographs in this time, by the following method:An electric arc was focused by a pair of seven-inch lenses upon the lens of an ordinary half-plate camera. A box with a glass front and back, containing the liquids and the growing drop, was placed immediately in front of the large lenses, and the drops were focused by the lens of the camera upon the ground-glass screen at the end of a slide forty-two inches long. This could be charged with four $10 \times 4$ plates (two $10 \times 8$ plates cut longitudinally), and then be drawn by hand from one end to the other of a seven-foot slide which protected the plates from light everywhere except at one place where a window $4 \times 1$ inches had been cut. Through this window the image of the falling drops was cast upon the moving plate. Just in front of the camera-lens a disk of card with an aperture near the edge was made to rotate at any desired speed by one of Cuttriss's P. 1 motors. Everthing was then started, and the speed of the motor and rate of dropping adjusted until the really intermittent but apparently continuous view of the phenomenon upon the ground plate was as desired. The slide was then rapidly drawn from end to end by hand, the speed being such as to obtain rather more than one complete cycle during the motion of the slide. In the photograph, of a portion of which Plate VI. fig. 1 is an exact copy, the exposures were at the rate of fourteen a second, and lasted about one five hundred and sixtieth of a second each. The 
$\cdot+\frac{1}{1} \cdot 3$

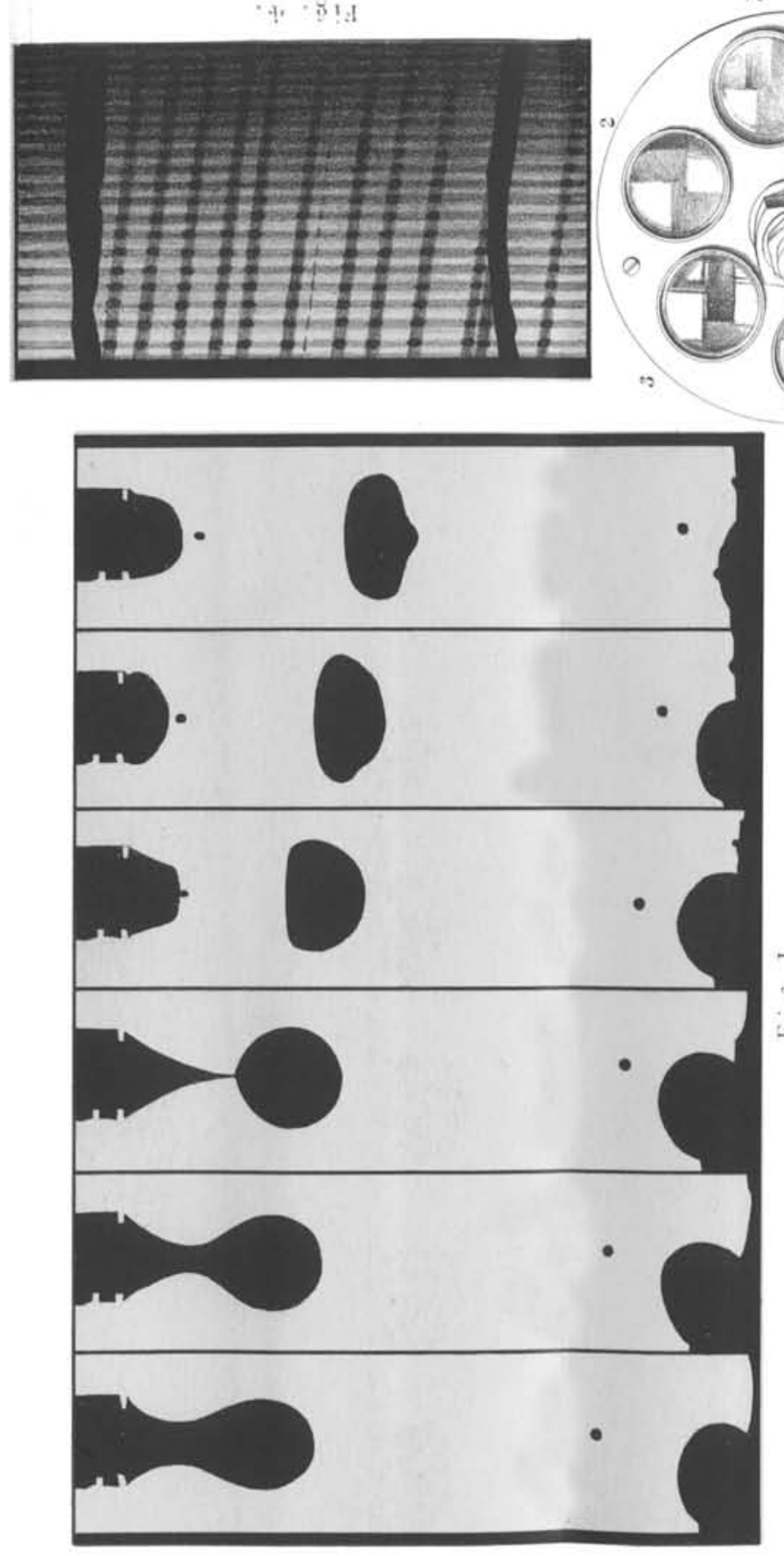

त्याe

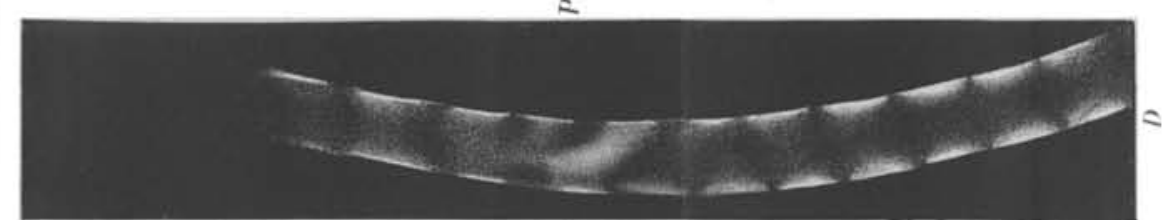

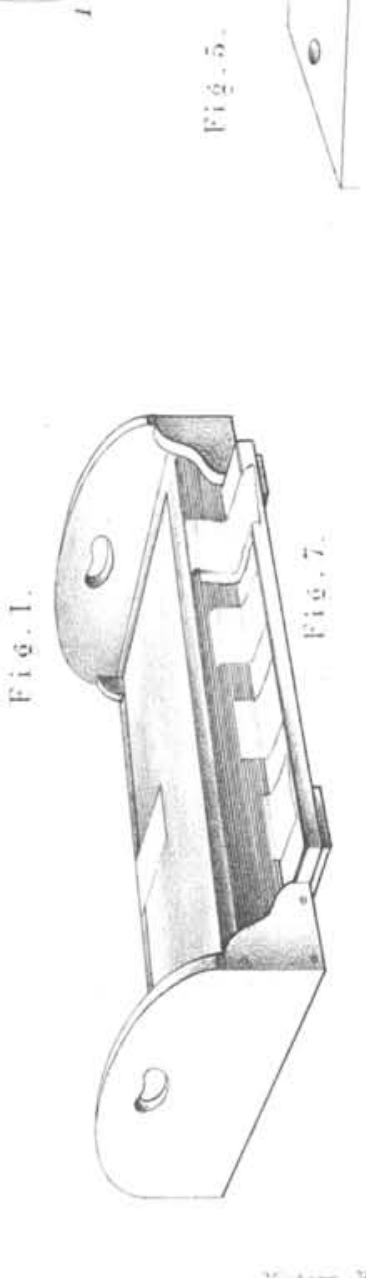

(a) $\theta$

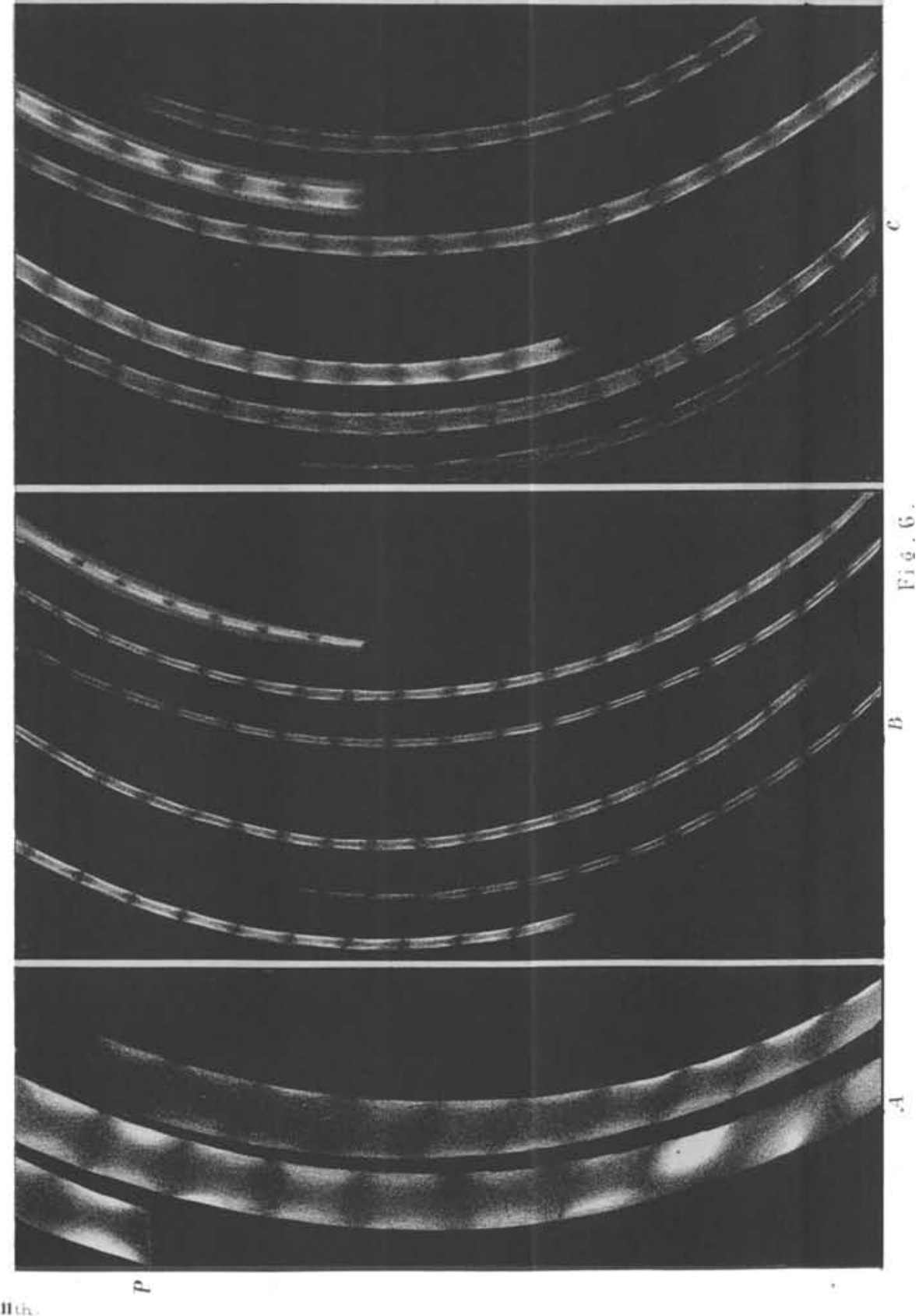


exposure was more than enough to make a perfectly black and white negative, and the outlines were clear and sharp. Another series taken at the rate of twenty a second with an exposure of one eight hundredth of a second each, in which forty-three separate views were taken in the complete cycle, was cut up into strips and mounted on a large disk of cardboard with forty-three equidistant and narrow slits near the edge. When the cardboard is made to rotate in front of a looking-glass, after the fashion of the thaumatrope, the original experiment is again perfectly presented, and all the features are evident without the necessity for using these objectionable liquids. The drop is seen to slowly enlarge until it is too heavy to be supported by the surface-tension, the form becomes unstable, a neck begins to develop, which gradually gets narrower until the drop separates. The free drop being suddenly released from the one-sided pull, vibrates as it falls, not in the manner figured in the text-books, between a prolate and oblate spheroid, but rather in a triangular fashion, with the base and vertex alternately uppermost, as recently described by $\mathrm{Ph}$. Lenard*. The falling drop reaches the water at the bottom of the box, where it vanishes for a time only, for it has not mixed with this water, and so it presently bounces out, as shown in fig. 1, after which it again falls into the water. Meanwhile the end of the neck from which the drop broke away has gathered itself together into the little drop or spherule so ably described by Plateau, which has an upward velocity imparted to it, since it separated from the upper or pendant drop after the falling drop had broken away. Moreover, just as the falling drop vibrates after it is released, so the pendant drop vibrates also and grows as it vibrates, coming into collision with the upward moving spherule, which it drives away by a blow. Fig. 2 is a reduced copy of the thaumatrope. The method described could be made more perfect by using films on rollers driven by the same motor that makes the card rotate, so that the separate photographs should neither overlap nor leave space unoccupied; but I did not make use of this refinement, as my object was simply to get the true outline in a particular experiment, and not to construct a piece of mechanism. The apparatus described was simply extemporized out of the materials at hand, and it answered my purpose perfectly.

2. As I wished in the lectures referred to above to show that exactly the same process goes on even when the finest jet of water breaks up into beads, though of course the process is hundreds or thousands of times more rapid, I was

* Annalen der Plysitk und Chimie, vol. xxx. 1887. 
Objects, and on the Oscillating Electric Spark.

anxious to obtain photographs of these forms which should be as sharp and as clear as the photographs already described.

Fig. 2.

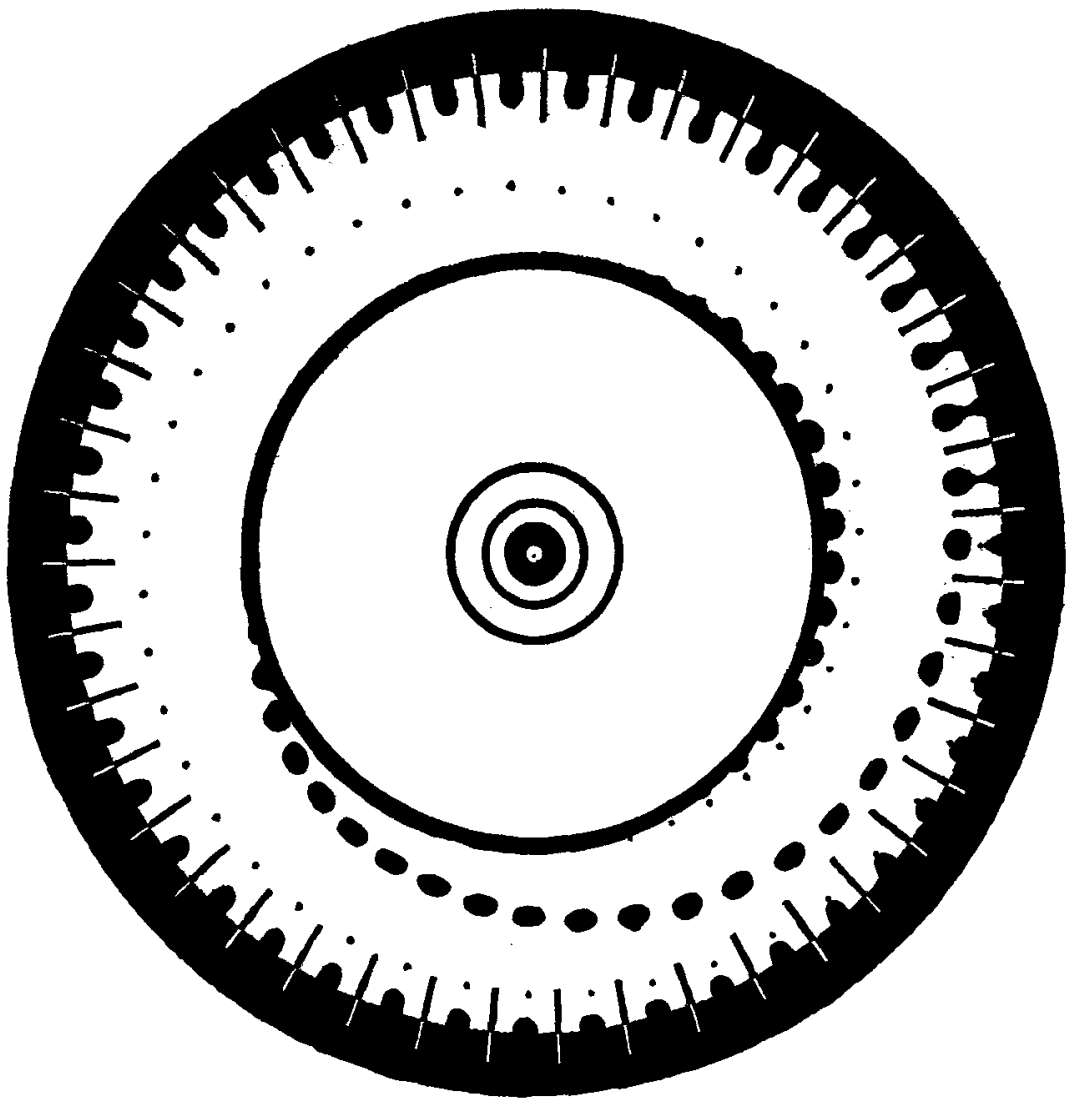

Mr. Chichester Bell described to me in a letter a method which he had used successfully for this purpose, which lis more especially interesting now, as Lord Rayleigh has recently exhibited photographs taken by a very similar method. Mr. Chichester Bell simply makes a small spark with one or two Leyden jars several feet away from the plate. The jet of water is allowed to fall between the spark and the plate, but as close to the plate as possible. The shadow cast under these conditions is perfectly sharp and will stand considerable magnification, and the light is quite sufficient to blacken the plate except when the water-drop protects it. Fig. 3 is an 
enlargement of one of these photographs. The water was broken up regularly by simply blowing into a key which whistled a note of 2730 complete vibrations a second, so that each drop moved to the position occupied by the next in the $\frac{1}{2730}$ of a second. Lord Rayleigh photographed jets of water by the spark with a camera and lens, using in addition a large condensing and field lens, so as to obtain sufficient light; but it appears that the glass of the lenses is not of much advantage, if any, because, as ho himself has since suggested, it absorbs so large a proportion of the ultra-violet rays that the gain by concentration is about balanced by the absorption of the most actinic rays.

3. Having found by the shadow method that there was an abundance of light from a comparatively feeble spark, I thought it possible that each half period of an oscillating spark might produce sufficient light to leave a clear record on a rapidly moving photographic plate of the shadow of small and rapidly moving objects. To put this to the test of experiment, the following arrangement was made. In

Fig. 3.

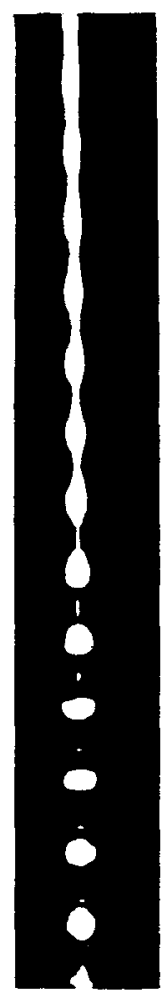
the first place an oscillating spark was formed between a pair of polished brass knobs about one tenth of an inch apart, by discharging a condenser of large capacity through one or two coils of gutta-percha-covered copper wire to give self-induction. Details of the electrical arrangements will be given at the end of these notes; but I may state here that the separate flashes of light in the spark followed one another at the rate of about 4500 a second. A "balf plate" was held in a recess in a disk of wood screwed to a whirling-table, so that it could be made to rotate in its own plane at a high speed. A cardscreen with a narrow slit was placed just in front of the plate, so that the light from the spark could fall on the plate through the slit. The jet of water was then formed just in front of the slit, and when the plate was rapidly revolving the spark was formed. The plate, on being developed, was found to have impressed upon it a picture like an open fan with the water- 
drops arranged in spiral lines. This method was not so convenient as a modification in which, instead of a glass plate spinning in its own plane, a flexible film was employed, wrapped round and held by two india-rubber bands upon a brass cylinder $1 \frac{1}{3}$ inches in diameter. This could be made to rotate at a very high speed by means of a light band from a whirling-table. Pl. VI. fig. 4 is a copy of a photograph obtained in this way. Here it will be seen that the intermittent light is automatically produced, and the period of the intermittence is constant for any particular apparatus. However, as carried out, the value of this method of observing the movements of rapidly moving bodies loses its practical value because the spark is alight during a large proportion of the time of each oscillation, so that it is by no means an instantaneous phenomenon.

4. In order to show the oscillating spark and to examine it by photography, I wished to have some more convenient means than the rotating mirror employed by Dr. Lodge. With this the observer is taken by surprise whenever a spark passes, for he does not know exactly in what direction to look, and therefore he finds it more difficult to recognize the peculiarities of the drawn-out spark than he would if he were certain that he would see the spark in the exact direction in which he was looking. Besides this it is not easy, when photographing the spark, to ensure that the whole phenomenon from the birth to the dying flickers of every spark shall be impressed upon the plate.

The method which I am about to describe appears to me to attain these ends more perfectly than any other with which I am acquainted, and it does not introduce any difficulties of its own.

A brass disk (Pl. VI. fig. 5) has six achromatic opera-glass lenses of about seven inches focus screwed into it, but not at the same distance from the axis. One pair, 1, 1, on opposite sides of a diameter are placed equidistant from the axis ; the next pair 2,2 are placed one tenth of an inch nearer the axis ; the third pair 3, 3 one tenth of an inch nearer still. The wheel is mounted on an axle, carrying a grooved pulley-wheel, and is accurately balanced. It may then be made to rotate, if necessary, at the very high speed of over a hundred turns a second. The spark is formed on one side of the plate, and a screen or photographic plate is held on the opposite side; and the two are so adjusted that the spark is focused upon the screen or plate. Now, when the disk is made to rotate, the image of the spark is drawn out into a beaded band; but as it is possible to turn the disk so fast that it has moved through

Phil. Mag. S. 5. Vol. 30. No. 184. Sept. 1890. 


\section{Prof. C. V. Boys on Photographs of Rapidly Moving}

an angle of nearly one hundred and eighty degrees during the existence of a spark, while to turn it through a right angle is perfectly easy, each lens will project a beaded are of a circle perhaps nearly half a turn in extent. If the separate lenses were all at the same distance from the axis, these six semicircular arcs would be projected on the top of one another and confusion would result; but as they are displaced by an amount which is about the same as the length of a convenient spark, the separate ares are just made to clear one another. Therefore, if the plate is large enough to take an arc of the length of sixty degrees, the whole record of the spark will afterwards be found upon it. By this means it is possible to make use of the high speed which is necessary to widely separate the several constituents of the oscillating spark without at the same time causing the record to be spoiled by the overlapping of the image formed by one lens by that produced by the next. A single pair of lenses, instead of six, would prevent the overlapping, but then to certainly obtain the whole record it would be necessary to make the plate receive an arc of one hundred and eighty degrees, which, on optical grounds, would be objectionable. If the sparks are to be shown on a screen it is best to make the spark in the axis of rotation, and show the complete circle or a large part of it; but if the image is to be photographed, it is best to place the spark exactly opposite one lens and use such a size of plate that when the disk is turned one image just begins to leave the plate on one side when the next is coming in on the other.

In order to make the most of a plate, it is convenient to expose it in a common camera-slide held in the hand or in a groove behind a card screen, with a curved aperture of such a size that the image from all three lenses can fall upon the plate. The plate can then be moved on by hand one stage after every spark, and five or six groups taken on one balf plate. Specimens of portions of a few of the photographs obtained are arranged together in Pl. VI. fig. 6.

Dr. Lodge has lately photographed oscillatory sparks, and has observed their peculiarities; I shall therefore do no more than merely mention the most striking features. The spark is obviously alight nearly all the time that it lasts, the intervals of darkness are short. The oscillatory spark proper is, I believe, always determined by what may be called a pilotspark, due to the discharge of the knobs and wires outside the self-induction.

The pilot-spark is well seen at $p$ in A, fig. 6 , which is a photograph taken with a very high speed and considerable 
Objects, and on the Oscillating Electric Spark.

magnification. That this pilot-spark is due to the discharge of the knobs is certain, because in the first place it is a quarter period behind the centre of the first spark of the oscillation proper, and in the second place because in a photograph taken under similar conditions, but after a small Leyden-jar had been directly connected to the terminals, the pilot-spark was far brighter than before and was even brighter than any of the succeeding alternating elements, while it occupied the same place, namely one quarter period before the centre of the first spark of the oscillation proper. The very exact analogy between the motion of the electricity in an oscillating spark and of the bob of a common pendulum may be worth tracing:-

The electric displacement gradually increases as the machine is worked until the electromotive force is sufficient to break the air-gap which held the electricity on one side.

The steady oscillation of the electricity then begins, and in a quarter period the electric velocity is at its greatest value, the current is strongest, or the spark is brightest; the current then gradually gets less until for a moment it cerses and the spark goes out.

The electric displacement is now nearly the same in amount as at first, but in the opposite direction, it therefore starts back again, and so swings backwards and forwards as the knobs become alternately+ and - (as is indicated in some of the photographs by the brighter glow alternately at each end of the spark), but getting less at every swing, owing partly to electrical resistance wastefully producing heat and partly to electromagnetic radiation which will give rise to oscillating currents in neighbouring conductors, especially if they have the same period, until at last the whole store of energy has been wasted and the electricity is at rest.
The displacement of the bob gradually increases as the thread which draws it to one side is pulled until the force is sufficient to break the thread which held the bob on one side.

The steady oscillation of the pendulum then begins, and in a quarter period the velocity is at its greatest value; the velocity then gradually gets less until for a moment the bob is at rest.

The displacement of the bob is now nearly the same as at first, but in the opposite direction; it therefore starts back again and so swings backwards and forwards, resting alternately on one side and on the other, but getting less at every swing, owing partly to resistance wastefully producing beat and partly to wave-motion transmitted through the supporting wall which will cause other pendulums to start swinging, especially if they have the same period, until at last the whole store of energy has been wasted and the bob is at rest.

In order to increase the total number of oscillations, I have introduced what I call a trap, which consists of a second airgap in the circuit kept open by a prop while a strong spring tends to close it. The spark-gap is then made very short, but the potential can be raised up to any degree that the conT 2 


\section{Prof. C. V. Boys on Photographs of Rapidly Moving}

denser will safely stand. A string tied to the prop is then pulled, and the spring completes the second gap so quickly that not more than one or two oscillations can take place after the spark hegins and before the filling of the air-gap at the trap. Thus a higher potential can be obtained than would be possible if the short working spark-gap alone determined the potential, while the resistance in circuit is less than before owing to the shortness of the spark.

Two sparks taken with the trap are shown in B,fig. 6 . Two longer sparks taken without a trap are reproduced in O, fig. 6. The gain in number of oscillations is not very great, as the measures by Messrs. Robson and Smith at the end of this paper show ; but there is a gain, especially as compared with a short spark taken without a trap. The trap, however, is practically useful in another way, it enables one to fix the instant at which the spark shall occur, which, besides being convenient, is important if for any reason the highest possible speed of rotation is required. While the lenses will run continuously at so low a speed comparatively as fifty or seventy revolutions a second, it would not be well to run them at high speeds for more than a few seconds together. $\mathrm{Br}$ the use of the trap this is possible, whereas, if the high speed had to be kept up during the long time that it takes to charge a condenser of so great a capacity to the sparking-point, there would be great risk to the bearings of the wheel of lenses. For instance, to obtain a spark about one tenth of an inch long from the condenser used in these experiments, from twenty to thirty turns of the handle of a large eight-plate Wimshurst machine had to be made.

Anomalous variations of brilliancy are not unusual, as may be seen in $A$, but a curious example is indicated by the letter $p$ in D. This represents the latter or dying portion of a spark taken on the same negative and under the same general conditions as $\mathrm{A}$. In this case it will be seen that the light instead of going out at the end of an oscillation travelled slowly across the gap to the other terminal, forming apparently a kind of ball-discharge.

One series of photographs I may here refer to, though the effect sought for is not so evident as I had expected. In this series a short vertical spark was formed, with its length parallel to the direction of the motion of the lens which at any time might be opposite to it. A magnetic field was produced in the line joining the spark and the lens. Then it was hoped that the current oscillating backwards and forwards would be largely deflected laterally alternately on either side so as to produce a zigzag impression. The arrangements 
were very imperfect, but there is a very slight lateral shift which I believe to be real, but it will be necessary to try the experiment again under more perfect conditions.

I must express my obligation to our lecture-assistant, $\mathrm{Mr}_{\mathrm{r}}$. R. Chapman, who has performed the whole of the purely photographic part of the experiments, and whose experience in this direction has been of very great service.

The following are the particulars of the apparatus that has been used. The electrical constants were determined by Messrs. W. G. Robson and S. W. J. Smith.

\section{Condenser.}

A wooden tray was made, as shown in fig. $7,28 \frac{1}{4}$ inches long and $16 \frac{1}{4}$ inches wide inside, but with the base projecting on each side so as to form a 22-inch square. A sheet of varnished glass of this size was laid upon the base, and then twenty-six pieces of thin window-glass $28 \times 16$ inches were piled on one another in the tray. The window-glass had been well washed, dried, and varnished while hot on each side all round the edge for a width of two inches. Pieces of tinfoil $24 \times 12$ inches were laid on each of the oblong pieces of glass, except the top one, and long tongues of tinfoil 3 inches wide were brought out alternately on the two sides. On one side all these tongues were brought out in the middle and bent down so as to rest on the square glass plate below ; on the other side they were brought out in four sets of three each with a space of two inches between each set. These were separately bent down to lie on the square glass plate below. By this means the capacity can be made variable in the proportions of $1,2,3$, and 4 by simply connecting the wire to $1,2,3$ or 4 of these electrodes. A strip of tinfoil lying over all the ends and held in contact by weights keeps them all connected except when a smaller capacity is required.

Total capacity 0.0979 microfarad.

Total capacity of battery of ten large jars 0.0451 microfarad.

Total capacity of small jar used to connect knobs (p. 355) .0026 microfarad.

\section{Self-Induction.}

Two coils, containing 330 yards each of No. 16 copper wire covered with gutta-percha to No. 7, were made use of in the form in which they arrived from the makers. The two coils are marked $\mathrm{C}$ and $\mathrm{U}$. The following are the dimensions in inches approximately:- 


$$
\begin{aligned}
& \text { Outside diam. Inside diam. Depth. }
\end{aligned}
$$

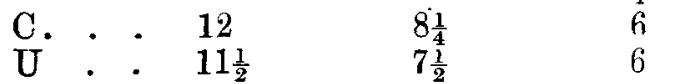

The resistances of the coils are:-

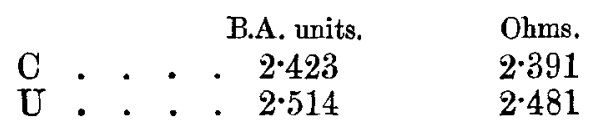

The self-inductions determined by Sumpner's method (Journal of the Soc. of Telegraph Engineers, 1887, fig. 5) were found to be

$$
\begin{gathered}
\mathrm{C} \\
\mathrm{U}
\end{gathered} \cdot \cdot \cdot 26 \cdot 89 \times 10^{6} \text { C.G.S. units. }
$$

In comparing the number of oscillations measured with those calculated from the electric constants given, experience showed that the photographs, such as those in fig. 6 , were not so suitable as one taken with the spark in the line of the axis of the wheel of lenses, because, though the definition along a radius was not so good in the latter arrangement, it was for the purpose of determining the intervals of darkness just as good, moreover it gave a much larger are on one plate which made it possible to obtain the centre on the plate, and therefore the angle between two points on the are, with greater accuracy. If the lenses were screwed into the face of a flat cone so that the axes of each should meet in the axis of rotation at the place of the spark, then definition would be equally perfect in all parts of the circle. I did at first intend to place the lenses in such a cone, but for various reasons the plate seemed preferable.

The comparison of the calculated number of oscillations with the number found is complicated by the relations between true ohms and B.A. units, as follows:-

If the condenser is standardized with reference to the B.A. unit of resistance, then, since the B.A. unit is 1.33 per cent. too small, the number expressing the resistance is too large and therefore the number expressing the capacity is too small, since one varies inversely as the other, and so the number expressing the capacity of such a condenser must be multiplied by 1.0133 to obtain the true capacity.

The self-induction determined by comparison with capacity and resistance is found from the expression

$$
\mathrm{L}=\mathrm{a} \text { number } \times r_{1} \times r_{2} \times \mathrm{C} \text {. }
$$

If the resistances $r_{1} r_{2}$ are given in true ohms, then, as the 
number expressing $\mathrm{C}$ is too small by 1.33 per cent., therefore the number expressing $\mathrm{L}$ is also too small by 1.33 per cent., and the nominal value of $\mathrm{L}$ must be multiplied by $1 \cdot 0133$. But if $r_{1}$ and $r_{2}$ are given in B.A. units, then, since these numbers are each too large by 1.33 per cent., therefore the number expressing $\mathrm{L}$ is also too large by this amount, since one of the resistances and the capacity will balance, and therefore the number expressing $\mathrm{L}$ must be divided by 1.0133 .

Now, the decrement being small, the numbers of oscillations in a second $n=\frac{1}{2 \pi \sqrt{\mathrm{LC}}}$; therefore, if $\mathrm{L}$ and $\mathrm{C}$ have each to be multiplied by $1 \cdot 0133, n$ should be divided by $1 \cdot 0133$; but, on the other hand, if one has to to be multiplied and the other divided by 1.0133 , then these corrections balance and $n$ requires no correction.

Messrs. Robson and Smith determined from the photographs the actual number of oscillations per second, and they determined also, assuming the microfarad to be correct, the number that ought to have been produced. The following are their results :-

\begin{tabular}{|c|c|c|c|c|}
\hline Observed number & 2293 & 3170 & 3264 & 2115 \\
\hline Calculated number & 2210 & 3126 & 3126 & 2210 \\
\hline $\left.\begin{array}{c}\text { Number of elementary } \\
\text { sparks in complete }\end{array}\right\}$ & 16 & 23 & 20 & 15 \\
\hline
\end{tabular}

These were all taken on half plates and were subject to the difficulty of centering. One spark was taken on a large plate, so that all six lenses produced images of the same spark. In this case the observed number was 1852, and the calculated number 1826. Now, ii this number is corrected by dividing it by 1.0133 , the calculated number becomes 1802 , showing the actual number to be about 2.7 per cent. too great. As window-glass was used for the condenser, which, owing to soakage, gives smaller capacities as the time of discharge is made smaller, it is probable that part of the discrepancy may be due to this ; but in the measurement of the capacity of the condenser the effect of soakage was made as small as possible by making, as far as such a thing could be done by hand, the contact of discharge instantaneous. The seif-induction, too, as measured, may have been slightly different to the selfinduction for oscillations at the rate of 1852 a second.

Mr. Smith has calculated the self-induction, using Prof. Perry's formula, given at the last meeting of the Physical Society, but the irregular form of the coils would not permit 
of an accurate number being obtained in this way. The figure obtained is about $51 \times 10^{6}$, a value which agrees with the observations better than that found by experiment.

I should add that I do not attach any importance to the diserepancies referred to. The experiments were made mainly with the view of showing the oscillating spark to an audience more clearly than is possible by the method of Dr. Lodge. For the purpose of measurement a window-glass condenser is not suitable at all, and I do not think the rotating lenses are so suitable as the method employed by Dr. Lodge, in which the plate itself is made to rotate in its own plane, for then the centre can be determined with the greatest accuracy.

The actual gain in number of sparks produced by the trap was found by making three experiments, in which all the conditions were the same except those specified.
A. No trap . . $\frac{1}{10}$ inch spark
B. No trap . - - $\frac{1}{2}$ inch spark
C. Trap giving ? $\left.\begin{array}{l}\text { potential } \\ \text { of } A \text {. }\end{array}\right\} \frac{1}{20}$ inch spark
32 elementary sparks. 29 " "

I should in conclusion state that the measurements given at the end of these notes were made after the meeting of the Physical Society at which the paper was read, and that some other additions have been made to the fourth part of these notes.

XXXI. On the Cheapest Form of Light, from studies at the Allegheny Observatory. By S. P. LANGLey and F. W. VERY*.

THE object of this memoir is to show, by the study of the radiation of the fire-fly, that it is possible to produce light without heat other than that in the light itself; that this is actually effected now by nature's processes; and that these are cheaper than our industrial ones in a degree hitherto unrealized. By "cheapest" is here meant the most economical in energy, which for our purpose is nearly synonymous with heat; but as a given amount of heat is producible by a a known expenditure of fuel at a known cost, the word

* Communicated by the Authors, to whom we are liliewise indebted for the cliches. 